\title{
Assessment of Childhood Domestic Injuries among Joint and Nuclear Families of Karachi
}

\author{
Asif Khaliq1, Amreen ${ }^{2}$, Shahroz Siddiqui ${ }^{3}$, Ghulam Mujtaba Nasir ${ }^{4}$ \\ ${ }^{1}$ Baqai Institute of Health Sciences, Baqai Medical University, Karachi, Pakistan \\ ${ }^{2}$ Department of Psychology, University of Karachi, Karachi, Pakistan \\ ${ }^{3}$ Department of Pharmacy Services, Aga Khan University Hospital, Karachi, Pakistan \\ ${ }^{4}$ Ministry of Health-Qassim, Buraidah, Kingdom of Saudi Arabia \\ Email: amreen_rao@hotmail.com
}

How to cite this paper: Khaliq, A., Amreen, Siddiqui, S. and Nasir, G.M. (2017) Assessment of Childhood Domestic Injuries among Joint and Nuclear Families of Karachi. Open Journal of Social Sciences, 5, 50-59. https://doi.org/10.4236/jss.2017.52006

Received: December 24, 2016

Accepted: February 3, 2017

Published: February 6, 2017

Copyright (c) 2017 by authors and Scientific Research Publishing Inc. This work is licensed under the Creative Commons Attribution International License (CC BY 4.0).

http://creativecommons.org/licenses/by/4.0/ (c) (†) Open Access

\begin{abstract}
To assess the frequencies and factors of domestic injuries among children aged less than 5 years. This is a cross sectional study, in which parents who have child less than 5 years of age were targeted. A total of 246 participants had provided satisfactory information and they were approached by nonprobability purposive sampling technique from January 2016 to June 2016. The data was entered in Excel and then imported to SPSS 19.0 for inferential analysis. In this study, $89.8 \%(\mathrm{n}=221)$ mothers and $10.2 \%(\mathrm{n}=25)$ father who had participated. $52.08 \%(\mathrm{n}=123)$ parents were from joint family. The different types of domestic injuries faced by children were fall (52\%), sharp cut (36\%), and burn (31\%) and Temporary fever, rashes and scratches were the most common consequence of domestic injury as experienced by $57 \%$ children. No any significant difference $(p>0.05)$ in the storage practices of different household hazardous item was observed among the parents living in joint and nuclear family system. Protecting children from domestic injury is a multi-dimensional approach. It needs parent's education, manufacturer guidance, Government regulation and joint community efforts for proper and safe storage of household items. These measures will aid in reducing the burden of childhood domestic injuries.
\end{abstract}

\section{Keywords}

Domestic, Injuries, Children, Under 5, Karachi

\section{Introduction}

Injuries are among the neglected from public health concern [1] [2] although has potential to be preventable [3] The total disease burden contributed by inju- 
ries is around $11 \%$ throughout the globe, as stated by the Global Burden of Disease, Injury and Risk Factor (GBD) report 2010 [4]. This burden of injury is not equally distributed and is more concentrated among Low-income and Middle-income countries (LMIC) [5].

Injuries and trauma has amplified the rate of hospitalization, mortality and disabilities [6] [7]. In countries like the United States, it is the injuries that cause death of a person in every 3 minutes. The cause of the injuries varies with respect to the age and is more pronounced among pediatrics and adolescents. According to the report of HCRQ (Healthcare Research \& Quality), injuries contributes to $17 \%$ of total medical visits in Emergency Department, of which overone quarter cases are of children and adolescents [8].

Every year more than 1 million children die because of preventable injuries [9]. There are variety of proven methods that could reduce the incidence and the severity of injuries among children and about $90 \%$ cases of injuries can be prevented by public awareness, environmental as well as engineering modification and also by enactment of legislation [8].

In LMIC (low middle income countries) no any policy is devised against the protection of children with household hazards injuries. The childhood domestic injuries are multifactorial and are associated to occur because of poor safety judgment of children about safety. Moreover, carelessness, laziness and fatigue of care giver, maternal depression and lack of safety measures for household hazards are also associated to cause childhood domestic injuries [9].

Injuries are most prevalent cause of disabilities, hospitalization and death among children. The incidence as well as burden of childhood injuries can be minimized by educating parents and other family members and by providing appropriate measure for the storage and disposal of household hazard. It is the parents that play an important role in reducing the incidence and burden of childhood domestic injuries and no any study has conducted on the pattern of childhood injuries in the joint and nuclear families of Karachi as well as in Pakistan. Therefore the basic purpose of this study was to access the pattern of childhood injury among children aged less than 5 years and to evaluate the difference in the practices of parents regarding domestic hazards protection.

\section{Methodology}

This is a cross sectional study that was conducted in different private sector OPD clinics of Karachi from January 2016 to June 2016. The data in this study was collected from all the parents who have any child aged 5 years or less and their child must be able to crawl, move or walk. Moreover, the parents who were permanent resident of Karachi and who were able to fill the questionnaire were included and they were approached by non-probability purposive sampling technique. However, parents who just have children less than 6 month were excluded, because at this age usually children are not able to move, crawl and walk by themselves. Beside this, parent who have under 5-year children with any physical or mental disability and those living in other cities or countries and 
those unable to fill the questionnaire were excluded. Since no any current and official information exist about the population of parent of children less than 5 years of age in Karachi, therefore keeping 95\% confidence interval, 5\% margin of error and response distribution of 50\%, the sample size of this study was calculated as 382 by RaoSoft Sample size calculator. A verbal and written informed consent was provided to all the participants before their full participation in this study. Beside this, they were allowed to withdraw from study anytime without prior notice.

The data in this study was collected from a self-made questionnaire that was adopted from a Nigerian and an Indian study regarding childhood domestic accidents [10] [11]. The questionnaires consist of 3 main sections that include: participant's demography, past 12 month childhood domestic injury assessment, and practices of parents regarding household hazardous material and substance storage. In first segment of the questionnaire the participants have to choose the appropriate category that were related to the participants and that were age, gender, family system and education level. In the second segment the participant have to mark all the injuries which their children had faced in last 12 months and its consequences. This segment composed of 10 dichotomous questions, out of which 6 were of injury type assessment and 4 were of injury effect assessment. However, the last segment composed of 5 items and each item has 4 options for the storage of a household hazardous substance or material, among these options only one was appropriate. Participant would get 1 point for appropriate storage practice, otherwise zero. The maximum score a participant can get is 5 out of 5 . The questionnaire was validated by a panel of expert by readability test and field test, the face validity of all the questions checked and revised before reliability testing. The reliability of the questionnaire was carried out by test-retest method on $10 \%$ of the sample and the cronbach alpha value calculated was 0.547. The data was collected from OPD clinics from 4 different hospitals of Karachi and was analyzed by Statistical Package for Social Sciences (SPSS) version 19.0 .

\section{Results}

In this study, a total of 427 parents were approached for participation who were waiting in the OPD (Outpatient Department) consulting clinics of selected private practitioner clinics and hospitals of Karachi. There were 398 parents, who fall under our inclusion criteria and were agreed to fill the questionnaire. Out of which 312 had return question, but 66 questionnaires were incomplete, therefore data analysis was carried out only in 246 questionnaires.

Table 1 indicated that $89.8 \%(\mathrm{n}=221)$ participants interviewed were mother of children less than 5 year, while rest of $10.2 \%(n=25)$ were father. Majority of the parents i.e. $64.22 \%(\mathrm{n}=158)$ parents have graduate level education, followed by post-graduate $15.85 \%$ and only $5.28 \%$ parents had 10 -year education level. There were $52.03 \%(\mathrm{n}=128)$ parents dwelling in joint family system and $47.97 \%$ $(\mathrm{n}=118)$ were living in nuclear family system. 
Table 1. Demographic profile of participants and their family.

\begin{tabular}{cccc}
\hline Variables & Categories & Frequency (n) & Percentage (\%) \\
\hline \multirow{2}{*}{ Parents } & Mother & 221 & $89.8 \%$ \\
& Father & 25 & $10.2 \%$ \\
Family Type & Joint Family & 128 & $52.03 \%$ \\
& Nuclear Family & 118 & $47.97 \%$ \\
& Matric & 13 & $5.28 \%$ \\
Parents Education & Inter & 36 & $14.63 \%$ \\
& Graduate & 158 & $64.22 \%$ \\
& Masters & 39 & $15.85 \%$ \\
\hline
\end{tabular}

Table 2 indicates that the family types are not associated with the type of injuries faced by their children. Moreover the storage practices of parents living in nuclear as well as in the joint family system is also not associated with their family type in most of the cases, except in 2 cases, i.e., Appropriate practices of electrical appliances are followed more in joint family and in contrast the nuclear family parents follow appropriate practices for Hazardous utensils storage.

As shown in Table 3, the mean score of the parents of both joint family as well as nuclear family regarding the appropriate storage practices of household hazardous substance was found to be $2.93 \pm 1.36$ and $2.95 \pm 1.31$. Moreover the inferential analysis by applying independent sample t-test gives $\mathrm{p}>0.05$; this means there is no significant difference in the storage practices of household hazardous material and substances among the parents dwelling in joint family and nuclear family.

Figure 1 indicates that among various types of injuries faced by the children less than 5 years of age, majority of the parents of both group responded that the fall accounts for $52 \%$ of injuries cases, followed by sharp cut (36\%) and burn (31\%). However less than 30\% parents responded that their children become victimize with other types of injuries like Poisoning, Road Traffic Accident, and animal bite and foreign body ingestion/insertion.

Figure 2 indicates that $57 \%$ parents responded that following domestic injury their children suffer from fever, rash and scratches followed by scar in $41 \%$ cases. Only one death was reported that represent $0.4 \%$ of the sample and the rate of deformity and fracture was $3 \%$.

Figure 3 indicates that majority of the parents correctly responded that they protect the hazardous utensils like knife, blades and other sharp material in appropriate places. On contrary, only $30 \%$ parents correctly store the electrical appliances.

\section{Discussion}

This cross-sectional survey based study was conducted in 4 different OPD clinics 
Table 2. Past 12 month childhood domestic injury assessment.

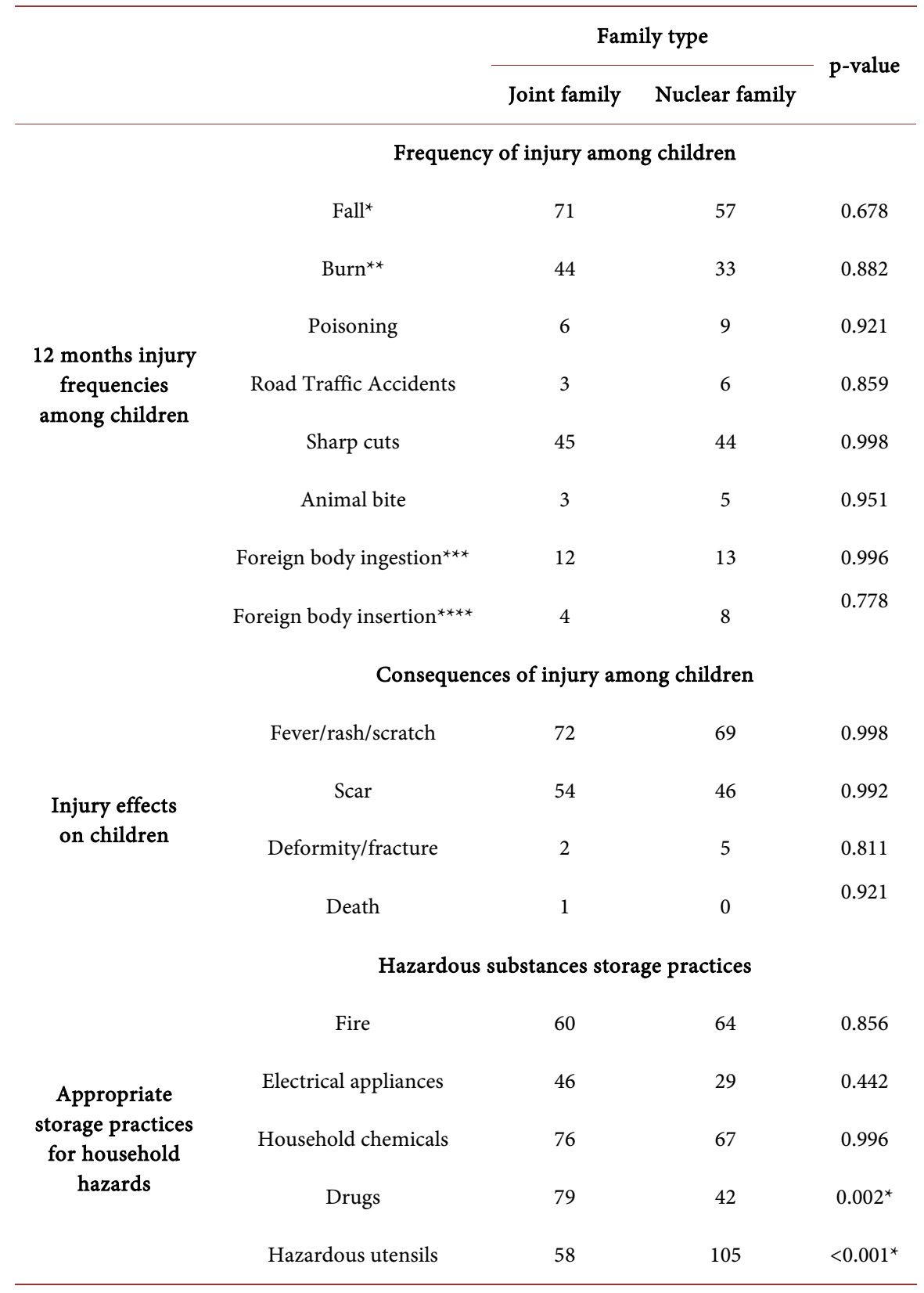

Asterik sign $\left({ }^{*}\right)$ indicate that there is significant association of storage practices with the family type. ${ }^{*}$ Fall means the jumping of children from bed, chair, tables, roof, wall and trees, but accidental fall from bed during sleep was excluded. ${ }^{*}$ Sunburn is excluded, and all type of burn because of food, food utensils, iron and other electrical appliances was included. ${ }^{* *}$ Foreign body ingestion include that children has swallowed and has not spitted any toy, coin, soil, cosmetics and any other noxious substance. Ingestion of Drugs, Multivitamins and supplements were categorized under poisoning. ${ }^{* * * *}$ Foreign body insertion include that children has inserted any toy, coin, soil, seeds, pins, cosmetics and any other substance.

Table 3. Joint and nuclear family household item storage practices.

\begin{tabular}{cccccc}
\hline Family type & N & Mean & S.D & df & p-value \\
\hline Joint family & 128 & 2.93 & 1.36 & 127 & $>0.05$ \\
Nuclear family & 118 & 2.95 & 1.31 & 117 & \\
\hline
\end{tabular}




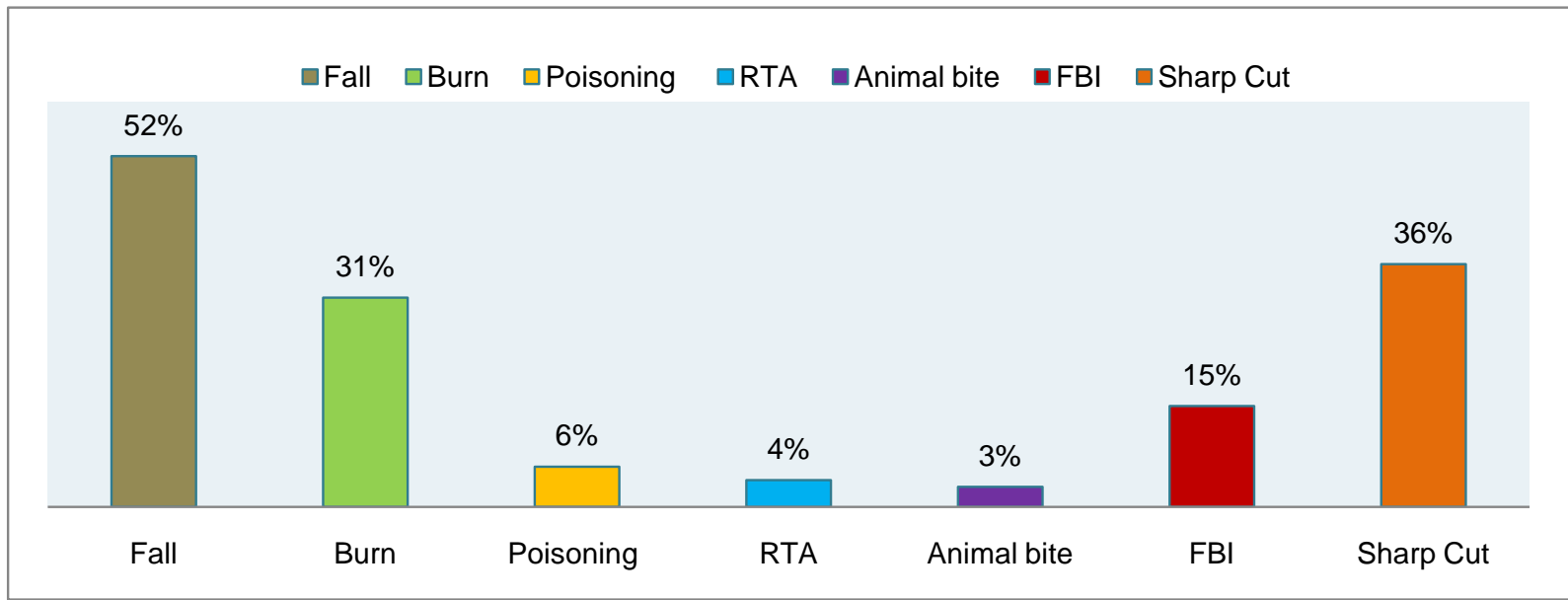

Figure 1. Prevalence of household domestic injuries among children. FBI = Foreign Body Ingestion/Insertion; RTA = Road Traffic Accident.

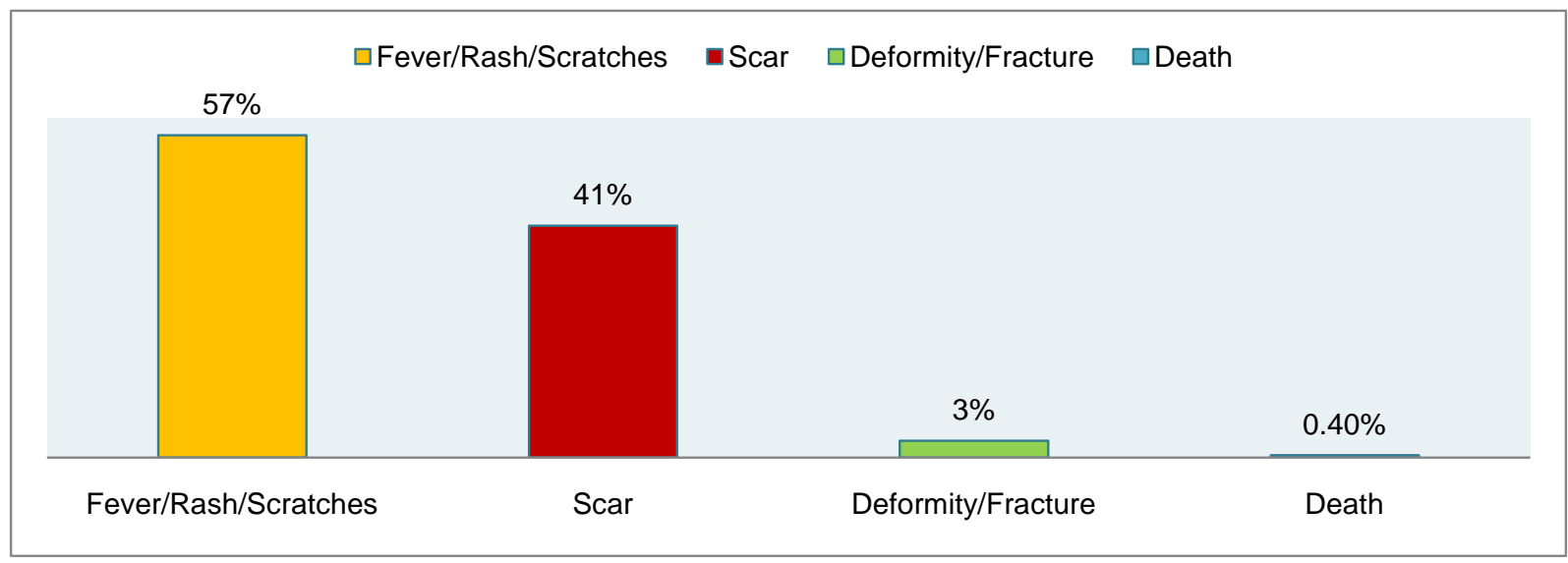

Figure 2. Consequences of household domestic injuries among children.

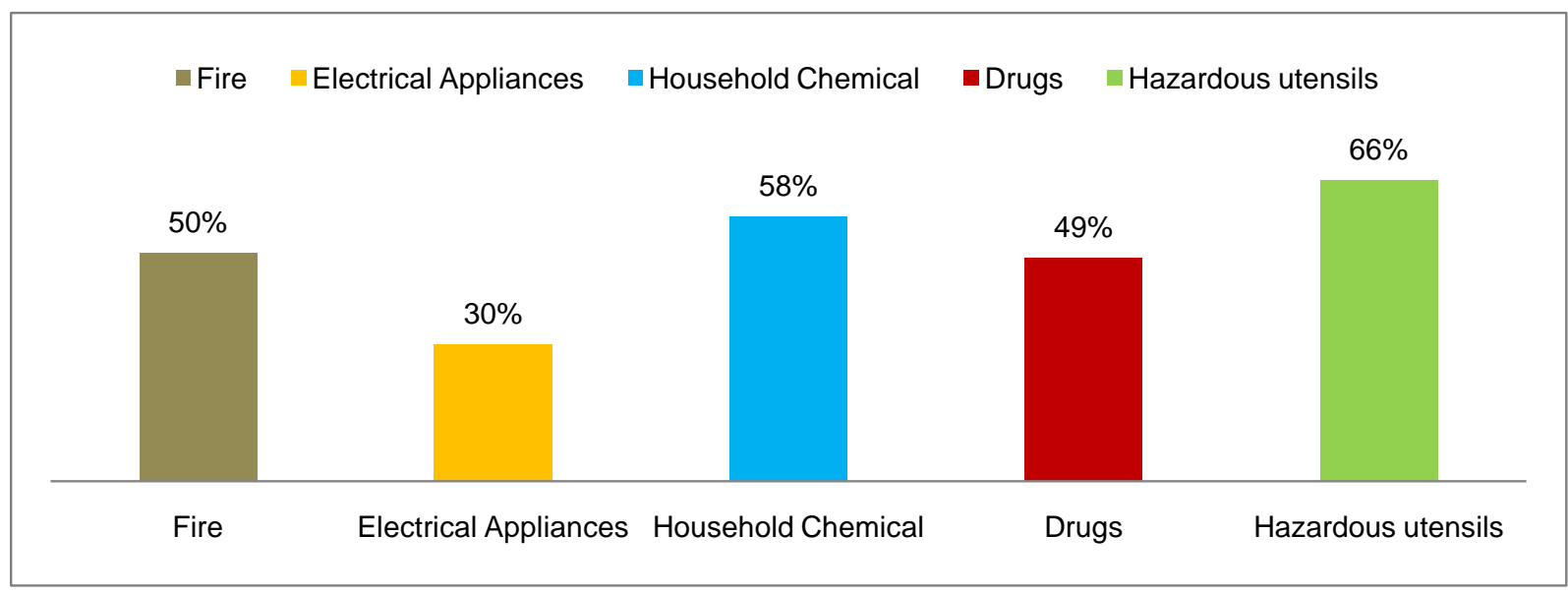

Figure 3. Parents practice regarding the storage of household hazardous substances.

of Karachi among the parents of children under 5 years. The basic purpose for this survey base study was to access the frequencies of domestic injuries among children under 5 years of age and to know about household hazardous substance 
and material storage practices among the parents living in joint and nuclear families of Karachi. The children of this age group usually remain in home and are not having sense of identifying hazardous and non-hazardous substances, and because of which the injuries rate among children under 5 years is high. Moreover, $85 \%$ cases of childhood injuries occur inside the home [12]. These were the reason for targeting the parents of under 5 years.

In this study, the leading cause of injuries identified among children were fall, cuts and burns and these causes are exactly similar to the leading cause identified by NSHP (National Health Survey of Pakistan) [12]. More than 50\% ( $\mathrm{n}=$ 128) parents responded that their children had episodes of fall in last 12 months. A 2-year retrospective study conducted by Phyllis et al. also reveals that fall is the leading cause of injury among children aged less than 4 years [13]. This is supported by another study conducted by Nimityongskul et al., that $75 \%$ of fall injury cases occur among children aged between 0 to 5 years [14]. The other leading causes of injuries among children were exposure to sharp cut (36\%) and burns (31\%). In the WHO-EMRO region, one third of the burn victims are of children belonging to age group 0 - 5 years [15]. Similarly, a population based survey in Bangladesh also depict highest incidence of burn among children aged 1 - 4 year. i.e., 782/100,000 among children under 5 and 288 among children aged less than 18 [16]. Regarding other types of injuries, like foreign substance ingestion, drug poisoning, animal bite and road traffic accidents. Only 4\% of parents responded that their children got injured because of road traffic accident. Adnan et al., in a systemic review presented that in South Asia $40 \%$ children aged 0 - 9 years are highly victimized because of road traffic accident injuries [17].

No any significant association $(\mathrm{p}>0.05)$ has been observed among the type of injuries and type of family system from the results of this study. A household survey conducted by Jannet et al., on 159 mothers of pre-school going children also reveal similar type of finding that the maternal social support and stress are not associated to reduce the risk of domestic injuries among children [18]. In contrast, a study conducted in United States in 1997-1998 reveal that having care from grandparents in family significantly reduces the risk of childhood domestic injuries [19].

The storage practices of parents regarding household hazardous substances dwelling in joint family and nuclear family system is not statistically significant ( $p>0.05$ ), this could be due to similar types of living attitude of parents and other family members. The mean score obtained regarding the storage practices of household hazardous substance and material among the parents was 2.93 \& 2.95 out of 5 . This means they are moderately taking precautions for reducing the risk of childhood domestic injuries. Although parents are already aware about the hazardous nature of many household materials and substances, therefore they need to be reinforced about the proper storage and disposal of all the household hazardous materials and substances. The reinforcement in parents about the proper storage and disposal of household hazardous materials and substances can be carried out by mass awareness campaign and also by enact- 
ment of legislation.

The childhood domestic injuries can be prevented by adopting 3 preventive strategies and this includes parent awareness and supervision, child education and environmental modification [20].

The injuries among the children can be prevented to great extent, and it needs some collaborative efforts of every member of community. These collaborative efforts include parental counseling on injury prevention and control, because the parental counseling produce positive outcome in preventing and controlling childhood injuries [21]. Moreover adopting various types of supervision behavior by parents could aid in reducing the incidence of unintentional injuries among children. These supervisory behaviors of parents can be visual, auditory and physical supervision, engaging children in non-injurious task and distracting them from risky games and activities [22].

Since it was not feasible to conduct household survey regarding the domestic injuries by visiting in different communities, because of the current safety and security conditions and also because of lack of funding and other resources, therefore this study was only conducted in 4 private practitioners clinics of Karachi among the parents who are waiting outside the OPD clinics for their and their children consultation, therefore this study is not actual representative about the issues faced by the parents of Karachi regarding childhood domestic injuries and their protective measure. Moreover, the cronbach alpha value of the questionnaire was 0.547 which reflect slightly weak internal consistency and some of the questions were asking about past 12-month injury record from the parents, based on this there can be chances of recall biasness among the parent's responses.

\section{Conclusion}

Injuries among the children are a major public health concern. Most of the injuries occur in pre-school children at domestic setting, when they are playing and are involve in recreational activities. Fall, burns, sharp cut, poisoning and insertion/ ingestion of foreign substance in oral cavity and nasal and ear opening are common cause of injuries among children. The incidence of injuries among children does not vary because of family structure and family system. Moreover the storage practices of parents for keeping the household hazardous substances and materials cannot influence on injury reduction and control. Supervisory role of parents and other family member, enactment of legislation and continuous public awareness can aid in reducing the burden of unintentional domestic injuries among pediatric population.

\section{Acknowledgements}

We would like to acknowledge Ms. Zona Israr, Asma Nezam \& Soofia Ishfaque who has helped us in data collection of this study.

\section{Conflict of Interest}

The authors declare no any conflict of interest. 


\section{References}

[1] Alonge, O. and Hyder, A.A. (2004) Reducing the Global Burden of Childhood Unintentional Injuries. Archives of Disease in Childhood, 99, 62-69. https://doi.org/10.1136/archdischild-2013-304177

[2] Gilbride, S.J., Wild, C., Wilson, D.R., Svenson, L.W. and Spady, D.W. (2006) Socio-Economic Status and Types of Childhood Injury in Alberta: A Population Based Study. BMC Pediatrics, 6, 1. https://doi.org/10.1186/1471-2431-6-30

[3] Centers for Disease Control and Prevention (CDC) (2006) Childhood Injury Report: Patterns of Unintentional Injuries in Children among 0 - 19 Year-Olds in the United States, 2000-2006, Atlanta, GA. Centers for Disease Control and Prevention (CDC), Atlanata.

[4] Higashi, H., Barendregt, J.J., Kassebaum., N.J., Weiser, T.G., Bickler, S.W. and Vos, T. (2015) Burden of Injuries Avertable by a Basic Surgical Package in Low- and Middle-Income Regions: A Systematic Analysis from the Global Burden of Disease 2010 Study. World Journal of Surgery, 39, 1-9. https://doi.org/10.1007/s00268-014-2685-x

[5] Peden, M.M. (2008) World Report on Child Injury Prevention. World Health Organization, Geneva.

[6] Ogendi, J.O. and Ayisi, J.G. (2011) Causes of Injuries Resulting in a Visit to the Emergency Department of a Provincial General Hospital, Nyanza, Western Kenya. African Health Sciences, 11, 255-261.

[7] El-Sayed, H., Zekry, O., Abbas, H., Hamid, S.A. and Hyder, A. (2012) Pattern and Severity of Childhood Unintentional Injuries in Ismailia city, Egypt. African Safety Promotion: A Journal of Injury and Violence Prevention, 10, 18-27.

[8] Villaveces, A., Mutter, R., Owens, P.L. and Barrett, M.L. (2013) Causes of Injuries Treated in the Emergency Department, 2010. Agency for Healthcare Research and Quality, Rockville, 1-8.

[9] Hyginus, E.O., Okechukwu, U.J., Victor, I.M., Christian, O.C. and Anthony. U. (2015) Epidemiology of Admitted Cases of Childhood Injuries in Nnamdi Azikiwe University Teaching Hospital Nnewi, Nigeria. Annals of Tropical Medicine and Public Health, 8, 272-275. https://doi.org/10.4103/1755-6783.162642

[10] Chaudhari, V., Srivastava, R., Moitra, M. and Desai, V. (2008) Risk of Domestic Accidents among under Five Children. The Internet Journal of Family Practice, 7.

[11] Oyedunni, S.A. and Olubunmi, I.M.O. (2013) Knowledge and Practices Relating To Domestic Accident among Mothers of Pre-School Children in Ibadan Southwest Local Government Area, Nigeria. IOSR Journal of Dental and Medical Sciences, 6, 49-55. https://doi.org/10.9790/0853-0634955

[12] Fatmi, Z., Kazi, A., Hadden, W.C., Bhutta, Z.A., Razzak, J.A. and Pappas, G. (2009) Incidence and Pattern of Unintentional Injuries and Resulting Disability among Children under 5 Years of Age: Results of the National Health Survey of Pakistan. Paediatric and Perinatal Epidemiology, 23, 229-238. https://doi.org/10.1111/j.1365-3016.2009.01024.x

[13] Agran, P.F., Anderson, C., Winn, D., Trent, R., Walton-Haynes, L. and Thayer, S. (2003) Rates of Pediatric Injuries by 3-Month Intervals for Children 0 to 3 Years of Age. Pediatrics, 111, e683-e692. https://doi.org/10.1542/peds.111.6.e683

[14] Nimityongskul, P. and Anderson, L.D. (1987) The Likelihood of Injuries When Children Fall out of Bed. Journal of Pediatric Orthopaedics, 7, 184-186. https://doi.org/10.1097/01241398-198703000-00014

[15] Othman, N. and Kendrick, D. (2010) Epidemiology of Burn Injuries in the East 
Mediterranean Region: A Systematic Review. BMC Public Health, 10, 83. https://doi.org/10.1186/1471-2458-10-83

[16] Mashreky, S.R., Rahman, A., Chowdhury, S.M., Giashuddin, S., Svanström, L., Linnan, M., Shafinaz, S., Uhaa, I.J. and Rahman, F. (2008) Epidemiology of Childhood Burn: Yield of Largest Community Based Injury Survey in Bangladesh. Burns, 34, 856-862. https://doi.org/10.1016/j.burns.2007.09.009

[17] Hyder, A.A., Amach, O.H., Garg, N. and Labinjo, M.T. (2006) Estimating the Burden of Road Traffic Injuries among Children and Adolescents in Urban South Asia. Health Policy, 77, 129-139. https://doi.org/10.1016/j.healthpol.2005.07.008

[18] Dal, S.J.A., Goodman, R.M., Glik, D. and Jackson, K. (2004) Childhood Unintentional Injuries: Factors Predicting Injury Risk among Preschoolers. Journal of Pediatric Psychology, 29, 273-283. https://doi.org/10.1093/jpepsy/jsh029

[19] Bishai, D., Trevitt, J.L., Zhang, Y., McKenzie, L.B., Leventhal, T., Gielen, A.C. and Guyer, B. (2008) Risk Factors for Unintentional Injuries in Children: Are Grandparents Protective? Pediatrics, 122, e980-e987. https://doi.org/10.1542/peds.2007-2995

[20] Morrongiello, B.A., Ondejko, L. and Littlejohn, A. (2004) Understanding Toddlers' In-Home Injuries: II. Examining Parental Strategies, and Their Efficacy, for Managing Child Injury Risk. Journal of Pediatric Psychology, 29, 433-446. https://doi.org/10.1093/jpepsy/jsh047

[21] Bass, J.L., Christoffel, K.K., Widome, M., Boyle, W., Scheidt, P., Stanwick, R. and Roberts, K. (1993) Childhood Injury Prevention Counseling in Primary Care Settings: A Critical Review of the Literature. Pediatrics, 92, 544-550.

[22] Morrongiello, B.A. and House, K. (2004) Measuring Parent Attributes and Supervision Behaviors Relevant to Child Injury Risk: Examining the Usefulness of Questionnaire Measures. Injury Prevention, 10, 114-118.

https://doi.org/10.1136/ip.2003.003459

\section{Submit or recommend next manuscript to SCIRP and we will provide best service for you:}

Accepting pre-submission inquiries through Email, Facebook, LinkedIn, Twitter, etc. A wide selection of journals (inclusive of 9 subjects, more than 200 journals)

Providing 24-hour high-quality service

User-friendly online submission system

Fair and swift peer-review system

Efficient typesetting and proofreading procedure

Display of the result of downloads and visits, as well as the number of cited articles

Maximum dissemination of your research work

Submit your manuscript at: http://papersubmission.scirp.org/

Orcontact jss@scirp.org 